\section{You've read the paper, now see the video}

These images of the surface of the Sun are stills from a short videotape that will be sent out with the 10 July issue of the Astrophysical Journal. All regular subscribers to the journal, the flagship publication of the American Astronomical Society, will receive a videotape, and subscribers outside the United States will be sent tapes in a format appropriate for their country.

On the tape are five segments related to papers in the journal. The solar images shown here form part of a movie that illustrates, in a series of high-resolution snapshots taken at roughly one-minute intervals, convective motion at the Sun's surface. The two images are complementary pictures of the same $30,000-\mathrm{km}$-square area showing regions of low and high surface magnetic field respectively. Although these still frames indicate that magnetic-field strength affects the convective cell structure, the movie as a whole, according to Alan Title of the Lockheed Palo Alto Research Laboratories in California, shows very plainly that the regions evolve differently over time: the less magnetized regions have a more pronounced

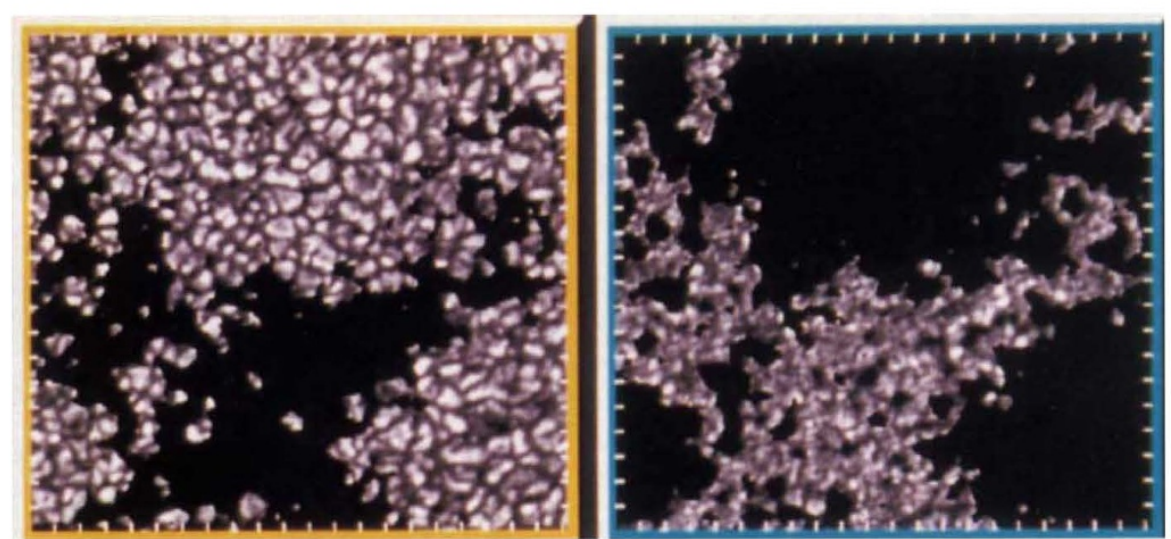

Areas of low (left) and high (right) magnetism on the Sun's surface.

cell structure, which changes on a faster timescale.

The use of movies in astronomy has been pioneered by theoretical astrophysicists performing computer simulations of, for instance, the formation and clustering of galaxies or the fate of matter spiralling into a black hole. Videotapes of such simulations have become a common feature of the annual meetings of the American Astronomical Society, and these movie presentations are much more than a gimmick. Both Title and Adrian Melott, a cosmologist from the University of Kansas whose simulation of galaxy formation is also in the current videotape, say that the movies reveal features and processes not apparent in a series of stills.

The increasing use of videotape attracted the attention of Helmut Abt, editor of the Astrophysical Journal, who last year began sounding out a number of potential 'authors' of videotape material. Further video editions of the journal are planned as and when needed, the salient question being whether the tapes are essential to a paper or merely ornamental. Authors must pay a 'page charge' of $\$ 1,000$ for each videotape segment used.

David Lindley

\title{
Genentech's stance on biodiversity riles staff
}

San Francisco. A group of scientists from Genentech Inc. have publicly criticized their company's opposition to a biodiversity treaty adopted at last month's Earth Summit in Rio de Janeiro.

The US biotechnology and drug industries have argued that parts of the biodiversity treaty protecting genetic resources in rain forests and other natural habitats also threaten US leadership in biotechnology. In a letter of 9 June to the US president, George Bush, G. Kirk Raab, president and chief executive of Genentech, praised him for refusing to sign the document because of concerns about intellectual property rights and regulatory constraints.

The letter angered Anthony J. Pelletier and other scientists, who learned about their company's position from local newspapers. "Many, many people from all levels of the company were upset by the way this was handled", says Pelletier.

On 26 June, Pelletier wrote to Bush, calling his position "short-sighted" and saying that Raab's views did not represent those of all the staff and scientists at Genentech, nor the industry as a whole. "We see the loss of the rain forest as the loss of potentially great discoveries, and the concomitant loss of profits", Pelletier wrote. "Many of us in biotechnology see protect- ing the diversity of life not merely as noble, but as good business as well."'

Pelletier broadcast his counter-position within Genentech by electronic mail and word of mouth, garnering support from 70 scientists and staff members. He says that more employees would have endorsed his letter if his laboratory were easier to find and he had not been asked to stop using electronic mail after reaching only about onefifth of the company's staff of 2,000.

Some of those who signed the letter from secretaries and technicians to scientific directors - felt betrayed by Raab's failure to consult them. The South San Francisco company, a pioneer in the young industry, has long fostered a spirit of internal democracy and social-mindedness through such programmes as its Friday afternoon parties and an on-site childcare centre.

Raab said he acted independently after consulting Genentech patent and law experts - because he felt strongly that Bush deserved commendation for making a risky and unpopular decision. "I didn't see it as a scientific issue," he said.

The letter of dissent has generated widespread discussion in the company. Many senior scientists have refused to take sides, saying they had no opinion "except the logical one - "let's save the planet". As one scientist commented, "we're all too busy trying to figure out science, which is a lot harder than figuring out treaties".

The incident has prompted Genentech to go out of its way to clarify its support for both the concept of biodiversity and the right to individual expression. Company officials let local media know that Raab had written a letter on 2 July in support of a bill before the US Congress that would catalogue natural species and monitor their activity. Raab said late last month that he agreed with the intent of the biodiversity treaty and even with the "vast majority" of Pelletier's points. The convention, which was signed by 172 nations, gives them the right to control access to their own genetic resources and would ensure some sort of mutually agreed payment in return for profitable goods and patents created from those resources.

In an interview last week, Raab said he believes passionately in preserving biodiversity. "But, at the same time, I don't believe mixing in industrial property rights is the least bit appropriate. If you dig up a little piece of dirt in Naples ... or pick a flower in Ecuador, I don't think there is necessarily a requirement that the country has some predetermined economic rights", he says.

Sally Lehrman 